\title{
Interacciones entre fecundidad y migración. Un estudio de las personas nacidas en el extranjero y residentes en Cataluña en $2007^{1}$
}

\author{
Daniel Devolder \\ Xiana Bueno \\ Centre d'Estudis Demogràfics \\ ddevolder@ced.uab.es \\ xbueno@ced.uab.es
}

\section{Resumen}

Este trabajo analiza las interacciones entre fecundidad y migración de la población inmigrada residente en Cataluña en 2007. Por interacciones entendemos no sólo los efectos del movimiento migratorio en el comportamiento reproductivo, sino también que la fecundidad en los países de origen pueda ser un determinante del proceso migratorio. Para ello, contemplamos la biografía reproductiva de las migrantes, tanto en el periodo previo como en el posterior al movimiento migratorio. Mediante los datos biográficos de la Encuesta Demográfica de Cataluña de 2007, se analiza la fecundidad de las mujeres inmigrantes en su ciclo de vida en relación con las autóctonas. Se utilizan tasas específicas de fecundidad por edad y se aplican modelos de duración que miden el riesgo relativo de que las mujeres inmigrantes tengan sus hijos antes o después del movimiento migratorio. El análisis considera la edad en el momento de la migración, el continente de origen y el estado conyugal cuando migran. Los resultados sugieren la identificación de cuatro efectos de la migración sobre la fecundidad: el efecto causal y el efecto de interrupción, como efectos premigratorios, y el efecto llegada y el efecto adaptación, como efectos postmigratorios.

Palabras clave: población inmigrada; población autóctona; fecundidad; biografía reproductiva; Cataluña.

1. Este texto se inscribe dentro de los proyectos de I+D: El aumento de la infecundidad en España y en Europa. Medición y análisis de sus determinantes y consecuencias (SEJ2007-63404), dirigido por el Dr. Daniel Devolder, y Comportamientos sociodemográficos diferenciales e integración social de la población inmigrada y de sus descendientes en España (CSO2008-04778/ SOCI), dirigido por el Dr. Andreu Domingo. Ambos proyectos son financiados por el Ministerio de Ciencia e Innovación. 
Resum. Interaccions entre fecunditat i migració: Un estudi de les persones nascudes a l'estranger $i$ residents a Catalunya l'any 2007

Aquest treball analitza les interaccions entre fecunditat i migració de la població immigrada resident a Catalunya l'any 2007. Per interaccions entenem, no només els efectes del moviment migratori sobre el comportament reproductiu, sinó també que la fecunditat en els països d'origen pugui ser un determinant del procés migratori. L'anàlisi considera la biografia reproductiva de les migrants, tant durant el període previ al moviment migratori com en el posterior. Mitjançant les dades biogràfiques de l'Enquesta Demogràfica de Catalunya de 2007, s'analitza la fecunditat de les dones immigrades durant el seu cicle de vida en relació amb les autòctones. S'utilitzen taxes específiques de fecunditat per edat i s'apliquen models de duració que mesuren el risc relatiu del fet que les dones migrants tinguin els seus fills abans o després del moviment migratori. L'anàlisi considera l'edat en el moment de la migració, el continent d'origen i l'estat conjugal quan migren. Els resultats suggereixen la identificació de quatre efectes de la migració sobre la fecunditat: l'efecte causal i l'efecte interrupció, com a efectes premigratoris, i l'efecte arribada i l'efecte adaptació, com a efectes postmigratoris.

Paraules clau: població immigrada; població autòctona; fecunditat; biografia reproductiva; Catalunya.

Résumé. Interactions entre migration et fécondité. Une étude de personnes nées à l'étranger et vivant en Catalogne en 2007

Nous étudions les interactions entre fécondité et migration pour la population étrangère résidant dans la région de la Catalogne (Espagne) en 2007. Par interactions nous entendons non seulement les effets des mouvements migratoires sur les comportements reproductifs, mais aussi le fait que la fécondité dans le pays d'origine puisse être un facteur du processus migratoire. Afin de pouvoir étudier ces interactions, nous considérons la vie reproductive complète des migrants, c'est à dire avant et après la migration. Nous utilisons une étude rétrospective qui inclut la biographie familiale complète aussi bien pour les femmes natives que nées à l'étranger. Nous calculons les taux de fécondité par âge et les risques de fécondité par âge et duration de résidence. Les résultats sont analysés en tenant compte de l'âge à la migration, du continent d'origine et de l'état matrimonial au moment de la migration. Les résultats suggèrent la présence de quatre effets de la migration sur la fécondité: l'effet causal et l'effet d'interruption dans la phase pré-migratoire; l'effet d'arrivée et l'effet d'adaptation après l'arrivée au lieu d'immigration.

Mots clé: population nés à l'étranger; la population autochtone; la fécondité; les histoires reproductives; la Catalogne.

\section{Abstract. Interactions between fertility and migration. Catalonia's 2007 foreign-born population}

This paper analyses interactions between fertility and migration using 2007 data on foreign populations living in the Spanish region of Catalonia. By interactions we do not only understand the effects of the migratory movements on reproductive behaviours, but also that fertility behaviour at place of origin can also have an impact on the migration process. In order to study these interactions, we choose to take all migrants' reproductive life of into consideration, that is to say, to examine all the time before and after the main migratory event. We use a retrospective survey with complete reproductive biographies, both for native-born and women born abroad. Age specific fertility rates and duration of stay 
specific risks of birth have been calculated. Results are analyzed taking into account age at migration, continent of origin and union status at time of migration.

Key words: foreign-born population; native population; fertility; reproductive biographies; Catalonia.

\section{Sumario}

Introducción Nacimientos hasta y desde la migración:

El estudio longitudinal de la fecundidad modelización

de las migrantes

Conclusiones

Consideraciones metodológicas

Referencias bibliográficas

Fecundidad antes y después de la

migración: una aproximación descriptiva

\section{Introducción}

La población inmigrada se caracteriza, en términos generales, por una estructura de edad joven, por lo que, una vez en el país de destino, cuenta con la mayor parte de su periodo reproductivo por delante. No obstante, un buen número de los colectivos de inmigrantes se caracteriza también por una maternidad temprana, lo que supone, en muchos casos, dejar hijos previos en los países de origen. Aunque, tradicionalmente, la fecundidad de las inmigrantes se ha estudiado a partir de los nacimientos en el lugar de destino, a la hora de estudiar su fecundidad tras la migración resulta de vital importancia conocer sus biografías reproductivas completas, es decir, si cuentan con hijos producto de la etapa premigratoria, así como saber en qué momento del ciclo de vida se efectúa la migración.

Los estudios realizados a partir de los registros oficiales de nacimientos proporcionan una muy veraz fotografía del momento considerado, sin embargo, obvian los importantes aspectos arriba mencionados. Por todo ello, el objetivo del presente análisis es entender la interrelación existente entre migración y fecundidad bajo tres objetivos específicos. En primer lugar, se observa la pauta de fecundidad de las mujeres durante toda su vida reproductiva, es decir, antes, durante y después de la migración. En segundo lugar, se aplica una perspectiva comparativa con las mujeres nativas, con el fin de averiguar si existe una convergencia en los comportamientos de las migrantes dependiendo de su edad en el momento de migrar. En tercer lugar, se examinan las diferencias observadas en relación con tres variables de interés: 1) según la edad de llegada a España de las mujeres inmigradas; 2 ) según su origen, mediante los tres agregados continentales más representativos (Europa, África y América), y 3) según su estado conyugal - en unión o no- en el momento de migrar; siempre tomando como comportamiento de referencia el de la población autóctona. 
Conviene, primero, esclarecer este último punto: de forma general, se puede comparar la fecundidad de las personas migrantes con la de la población de origen o de destino. Comparar la fecundidad de las mujeres migrantes con la de aquellas compatriotas que permanecen en sus países de origen es un ejercicio de gran interés, aunque no sin pocos obstáculos en el tratamiento y la fiabilidad de los datos, si es que hay disponibilidad. Sin embargo, se cae en la limitación inequívoca de que no se están comparando a las mismas mujeres, y ello se convierte en agravante si se tiene en cuenta la consabida selección del perfil sociodemográfico y económico como característica intrínseca a todo migrante internacional. La perspectiva comparada con la población autóctona aporta la posibilidad de establecer una referencia constante sobre la cual elaborar conclusiones aplicadas al contexto de la sociedad de destino.

Pero, sin duda, el poder descomponer la fecundidad según la edad a la llegada de las mujeres migrantes es uno de los factores de mayor interés en este análisis, pues permite al mismo tiempo examinar cuál es el efecto no sólo del hecho migratorio, sino también del tiempo de residencia en España sobre el comportamiento reproductivo. El análisis que aquí se plantea permitirá hacer aparecer el efecto que tiene la migración como discontinuidad en el ciclo de vida y reproductivo de un mismo colectivo de mujeres migrantes, pudiendo comparar sus niveles de fecundidad antes, durante y tras el proceso migratorio. No obstante, se concibe también la posible existencia de una «interacción", donde no sólo la migración tiene un efecto sobre la fecundidad, sino donde el propio comportamiento reproductivo pueda repercutir en el proyecto migratorio.

Finalmente, la observación detallada por edad en la llegada, por origen y por estado conyugal en el momento de la migración, permitirá evaluar cuan heterogéneos son los comportamientos demográficos según estas tres características, así como delimitar diferencias y similitudes entre ellos y con la población autóctona.

Tras algunas referencias introductorias, teóricas y metodológicas, el análisis de resultados se estructura en dos grandes bloques. En primer lugar, y desde una aproximación descriptiva, se mide la fecundidad de las migrantes, tanto previa como posterior a la migración atendiendo al momento del ciclo de vida en que la migración se produce, con el fin de identificar los posibles efectos en las pautas reproductivas. En segundo lugar, se aplicará el análisis multivariable mediante modelos de regresión logística en tiempo discreto, para determinar el riesgo de que las mujeres inmigrantes tengan hijos en función de la duración de su estancia y tomando como referencia a las mujeres nativas.

\section{El estudio longitudinal de la fecundidad de las migrantes}

La literatura científica internacional ha puesto de manifiesto en innumerables ocasiones cómo el incremento del tiempo de residencia en el país de destino de los migrantes constituye un valor seguro en el camino hacia la integración —asimilación desde el contexto anglosajón-(Gordon, 1964). Llevada al 
plano del comportamiento reproductivo, esta máxima supondría la asunción de que, a mayor tiempo de estancia, más se asemejan las pautas reproductivas de las migrantes a las de la población nativa.

Trabajos previos a nivel internacional (Anderson, 2001; Kulu, 2003; Lindstrom y Giorguli, 2007; Milewsky, 2007; Roig y Castro, 2007; Castro y Rosero-Bixby, en prensa) han destacado las diferentes corrientes teóricas que enmarcan el estudio de la fecundidad diferencial de la población inmigrada. Dicha literatura ha demostrado la complementariedad de las diferentes perspectivas teóricas (adaptación, selección, interrupción, interrelación de eventos, socialización y legalidad) para alcanzar una visión completa de la interacción entre los procesos migratorio y reproductivo.

La hipótesis de adaptación es la que cuenta con mayor respaldo científico y sostiene que las mujeres inmigradas adaptan gradualmente su comportamiento reproductivo al de la sociedad de acogida. Por otra parte, algunos autores hablan de la hipótesis de estructura de oportunidades como aquella que justifica los cambios en la fecundidad a través de la influencia que supone el contexto socioeconómico y político de destino (Frank y Heuveline, 2005). En cambio, Milewsky (2007) o Kulu (2003) consideran que ambas hipótesis hacen referencia a un mismo proceso, caracterizado en cierto modo por una resocialización basada en la conciliación con unas nuevas circunstancias sociales, políticas y laborales en las que se desenvuelve el migrante y a las cuales adapta su comportamiento fecundo.

Se ha generalizado el supuesto de que las mujeres migrantes son de por sí seleccionadas, en tanto que responden a unas preferencias reproductivas más cercanas de antemano a las del país de destino que a las de las no migrantes en origen. Esta hipótesis considera características como la edad, el estado civil, la actividad, el nivel educativo, las ambiciones de movilidad social o las preferencias familiares (Milewsky, 2007). Las mujeres migrantes se caracterizarían generalmente por un retraso de la unión, una reducción de la fecundidad y un aumento de la actividad laboral (Lindstrom y Giorguli, 2007). La hipótesis de interrupción defiende que la fecundidad baja en un periodo inmediatamente previo y posterior al hecho migratorio, dados los costos - personales y económicos-asociados a la migración (separación de la pareja, interrupción de la actividad económica, etc.).

Casi como continuación natural a la hipótesis de interrupción, le corresponde la de interrelación de eventos que considera que una alta fecundidad tras la migración es el producto de la confluencia de eventos en un mismo momento (Milewsky, 2007). Normalmente hace referencia a aquella migración cuyo objetivo es la formación de la pareja o, especialmente, la reunificación familiar (Roig y Castro, 2007).

La hipótesis de socialización considera que las primeras generaciones que encabezan una migración mantienen las pautas reproductivas dominantes en origen (Milewsky, 2007; Kulu, 2003). En base a esta misma hipótesis, de quienes migran durante su infancia y de las segundas generaciones se espera un comportamiento reproductivo más cercano a los niveles del país de destino. 
Por último, la hipótesis de legalidad se presenta como una relación causal entre la migración internacional, el estatus legal y los eventos demográficos, en este caso los nacimientos. Se basa en el hecho que las mujeres inmigradas indocumentadas aumentan su fecundidad en el momento de llegar al destino, con el propósito de adquirir algún beneficio para la residencia legal en el país (Bledsoe, 2004; Bledsoe et al., 2007).

En perspectiva longitudinal, se ha observado, para otros países con larga tradición inmigratoria, cómo, en términos generales, la fecundidad de las migrantes desciende en el momento de la migración y el periodo inmediatamente anterior - hipótesis de interrupción-, como consecuencia se intensifica tras los dos años de residencia -hipótesis de interrelación de eventos- y vuelve a decaer o a estabilizarse durante los restantes años de estancia, con lo cual se aproxima a las pautas de la población nativa -hipótesis de adaptación- (Carter, 2000; Kahn, 1994; Lindstrom y Giorguli, 2007; Parrado y Morgan, 2008). En el contexto europeo, la literatura se ha centrado en los procesos de reagrupación familiar y formación de la pareja como factores que explican la alta fecundidad de las inmigrantes tras la interrupción que supone la migración (Anderson, 2001; Kulu, 2003; Alders, 2000; Toulemon, 2004).

El grueso de la literatura hasta entonces se ha centrado siempre en el periodo postmigratorio, con el fin de observar si el comportamiento reproductivo de las mujeres migrantes, una vez se encuentran en el país de destino, se asemeja o no al de la población autóctona, tratando de vislumbrar signos de convergencia

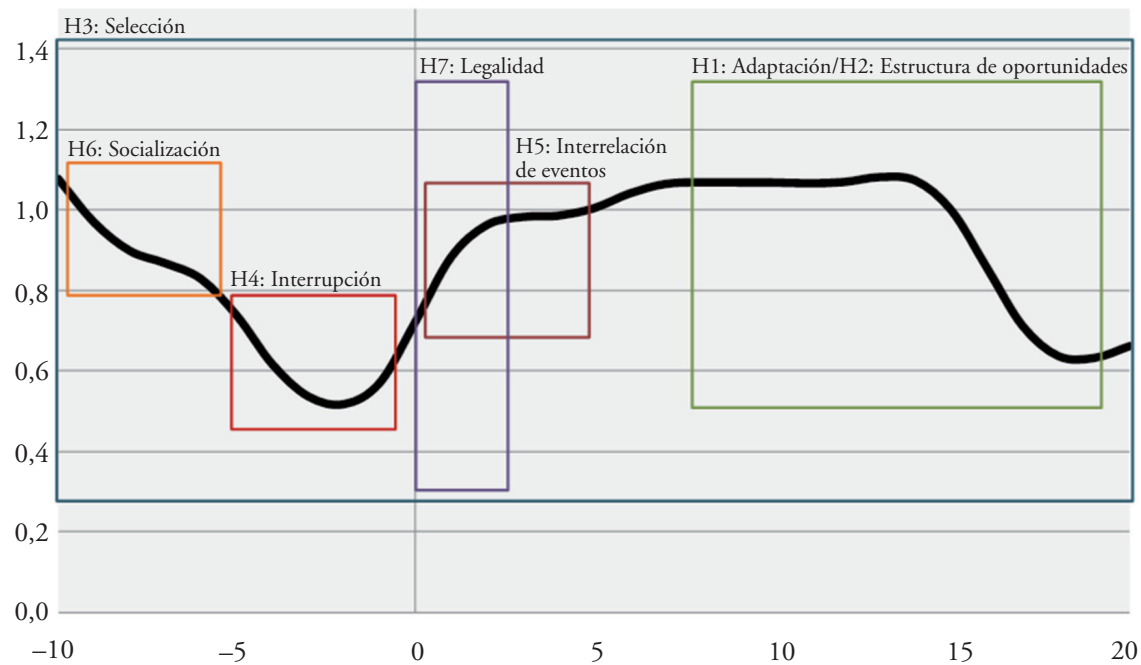

Figura 1. Hipótesis explicativas en el estudio de migración y fecundidad, en función del momento de la migración.

Fuente: Elaboración propia. 
o adaptación. Se trata de una pregunta de investigación válida. Sin embargo, la convergencia es sólo uno de los posibles efectos que la migración puede generar sobre la fecundidad de las migrantes. En este trabajo, se considera importante tener en cuenta una perspectiva temporal que contemple también el periodo premigratorio, ya que lo que podría interpretarse como un proceso de adaptación en la fecundidad de las migrantes, puede ser sólo la consecuencia de una interrupción de la misma a causa del movimiento migratorio. En otras palabras, si las migrantes posponen su fecundidad debido a la migración y, una vez en el país de destino, la recuperan generando un importante incremento y un descenso consiguiente, ese descenso puede ser identificado de forma errónea como un indicio de adaptación.

En definitiva, son menos los trabajos científicos que han contemplado longitudinalmente la fecundidad de las mujeres antes y después de migrar (Alders, 2000; Toulemon, 2004). Unos trabajos de referencia en el planteamiento del análisis longitudinal de la fecundidad de migrantes y que aquí se han tomado como modelo metodológico son los de Toulemon (2004) y Toulemon y Mazuy (2006) para el caso francés. En ellos se sostiene que, aunque tradicionalmente la comparación de la fecundidad entre mujeres nativas e inmigrantes se ha hecho a través del ISF, éste no es el indicador más apropiado, pues no tiene en cuenta la discontinuidad que supone el hecho migratorio en el ciclo reproductivo de las mujeres y, por tanto, sobrestima la fecundidad de las migrantes. Esta idea se sustenta en las hipótesis de interrupción e interrelación de eventos, según las cuales la fecundidad de las mujeres antes de la migración es baja, pero, dado que la migración está asociada a menudo con la formación de la familia (reagrupación familiar, nuevas uniones, etc.), la fecundidad se eleva tras la llegada al país de destino.

\section{Consideraciones metodológicas}

\section{Encuesta Demográfica de Cataluña (ED)}

En base a la representatividad de la muestra de población inmigrada, pero sobre todo por el carácter longitudinal de la fuente y la información de la que dispone, se ha seleccionado la Encuesta Demográfica de Cataluña como la fuente que mejor se adecúa al objeto de estudio. Las mujeres inmigradas en Cataluña representaban, en 2007, el 19,6\% de todas las mujeres inmigradas en España y los nacimientos de madre extranjera, suponían un 23,1\% de todos los nacimientos de este tipo. Ello nos autoriza a trabajar con Cataluña como territorio representativo cuyos resultados se puedan extrapolar a lo que sucede en el conjunto del territorio español. De cualquier modo, constituye un caso plenamente justificado para un estudio, tanto empírico como teórico, de la fecundidad de las mujeres inmigradas.

La Encuesta Demográfica 2007 (desde ahora ED) procedente del Instituto de Estadística de Cataluña (IDESCAT), es la encuesta de carácter longitudinal más completa en características demográficas desde la pasada 
Encuesta Sociodemográfica de 1991 elaborada por el INE. A pesar de no estar específicamente diseñada para el análisis de la población inmigrada, la ED cuenta con una muestra significativa de población procedente del extranjero y, además, permite su comparación con la población autóctona. La muestra de población nacida en el extranjero de la ED es de 3.771 individuos de un total de 27.911 registros, lo que supone un $14 \%$ del tamaño muestral total de la encuesta.

\section{Análisis descriptivo: fecundidad por edad}

En el análisis descriptivo, se han calculado tasas específicas de fecundidad por edad, según origen y edad a la llegada de la madre inmigrante. La muestra de mujeres inmigrantes para este primer ejercicio se seleccionó bajo el criterio de ser mujeres nacidas en un país extranjero que tuvieran hijos entre 1986 y 2006. La categoría de referencia «nativas» la constituyen tanto aquellas mujeres nacidas en Cataluña, como las nacidas en el resto de España y residentes en Cataluña. Tras la selección de la muestra, se transformó la base de datos a un formato de personas y nacimientos que facilitara el cálculo de las tasas específicas.

El volumen de nacimientos que la ED registra para el periodo 1986-2006 es de 5.998, de los cuales 1.449 (el 24,1\%) corresponde a madres nacidas fuera de España, tal y como muestra la tabla 1. Como es lógico, la mayor parte de estos nacimientos de madre inmigrante $(36,1 \%)$, independientemente de si tuvieron lugar en origen o en destino, corresponden al grupo de mayor edad - 523 nacimientos de madres llegadas con más de 33 años. Una quinta parte de ellos $(20,8 \%)$ corresponden a mujeres que llegaron a España con menos de 23 años.

Se debe señalar que el criterio de clasificación de las mujeres inmigrantes internacionales según la edad de llegada hace referencia al año de llegada a España, y no al año de llegada a Cataluña, por considerar que el evento clave es la migración desde el país de origen y no sucesivos movimientos internos. Ello implica la asunción, no necesariamente válida, de que la llegada a España se produce desde el país de origen y no desde otro lugar.

\section{Análisis multivariable: modelos de duración}

En el análisis multivariable, se mide el riesgo relativo de que una mujer inmigrante tenga un hijo, en relación con el mismo riesgo para las mujeres autóctonas, en función del tiempo transcurrido hasta y desde la migración para las primeras y controlando por edad para ambas. Se han seleccionado todas las mujeres - nativas e inmigrantes - y se ha aplicado el análisis de regresión logística en tiempo discreto o los también llamados «modelos de duración». Para ello, se han transformado los datos en registros sobre personas y año y se ha calculado una variable dicotómica que indicara el valor 1 si se produce un nacimiento y el valor 0 si no se produce. El momento cero o de inicio de la 
Tabla 1. Distribución de la muestra por edad en el momento de ser madres y origen (nativas e inmigrantes según edad a la llegada), Cataluña 1986-2006

\begin{tabular}{|c|c|c|c|c|c|c|c|c|c|c|}
\hline \multicolumn{11}{|l|}{ Nacimientos } \\
\hline & & \multirow[b]{2}{*}{ Nativas } & \multirow[b]{2}{*}{ Inmigrantes } & \multicolumn{6}{|c|}{ Edad en el momento de migrar } & \multirow[b]{2}{*}{ Total } \\
\hline & & & & $\begin{array}{l}0-12 \\
\text { años }\end{array}$ & $\begin{array}{c}\text { 13-17 } \\
\text { años }\end{array}$ & $\begin{array}{c}\text { 18-22 } \\
\text { años }\end{array}$ & $\begin{array}{c}23-27 \\
\text { años }\end{array}$ & $\begin{array}{c}28-32 \\
\text { años }\end{array}$ & $\begin{array}{l}\text { Más de } \\
33 \text { años }\end{array}$ & \\
\hline \multirow{8}{*}{$\begin{array}{l}\text { Edad en el } \\
\text { momento de } \\
\text { ser madres }\end{array}$} & $15-19$ & 76 & 154 & 4 & 12 & 28 & 50 & 48 & 12 & 230 \\
\hline & $20-24$ & 424 & 445 & 10 & 19 & 79 & 110 & 103 & 124 & 869 \\
\hline & $25-29$ & 1.432 & 415 & 16 & 13 & 48 & 106 & 78 & 154 & 1.847 \\
\hline & $30-34$ & 1.733 & 274 & 20 & 6 & 26 & 43 & 57 & 122 & 2.007 \\
\hline & $35-39$ & 743 & 126 & 7 & 3 & 8 & 5 & 20 & 83 & 869 \\
\hline & $40-44$ & 129 & 31 & 0 & 1 & 0 & 2 & 3 & 25 & 160 \\
\hline & $45-49$ & 12 & 4 & 1 & 0 & 0 & 0 & 0 & 3 & 16 \\
\hline & Total & 4.549 & 1.449 & 58 & 54 & 189 & 316 & 309 & 523 & 5.998 \\
\hline \multicolumn{11}{|c|}{ Efectivos de mujeres (15-49) } \\
\hline & & & & \multicolumn{6}{|c|}{ Edad en el momento de migrar } & \\
\hline & & Nativas & Inmigrantes & $\begin{array}{l}0-12 \\
\text { años }\end{array}$ & $\begin{array}{c}\text { 13-17 } \\
\text { años }\end{array}$ & $\begin{array}{c}18-22 \\
\text { años }\end{array}$ & $\begin{array}{c}23-27 \\
\text { años }\end{array}$ & $\begin{array}{c}28-32 \\
\text { años }\end{array}$ & $\begin{array}{l}\text { Más de } \\
33 \text { años }\end{array}$ & Total \\
\hline \multirow{8}{*}{$\begin{array}{l}\text { Edad en el } \\
\text { momento de } \\
\text { ser madres }\end{array}$} & $15-19$ & 15.274 & 4.789 & 310 & 394 & 1.152 & 1.514 & 957 & 462 & 20.063 \\
\hline & $20-24$ & 17.054 & 4.964 & 217 & 187 & 819 & 1.527 & 1.079 & 1.135 & 22.018 \\
\hline & $25-29$ & 18.535 & 4.403 & 177 & 105 & 355 & 1.037 & 1.094 & 1.635 & 22.938 \\
\hline & $30-34$ & 18.800 & 3.476 & 158 & 69 & 182 & 378 & 730 & 1.959 & 22.276 \\
\hline & $35-39$ & 18.352 & 2.545 & 143 & 61 & 119 & 157 & 242 & 1.823 & 20.897 \\
\hline & $40-44$ & 17.522 & 1.712 & 98 & 57 & 81 & 127 & 91 & 1.258 & 19.234 \\
\hline & $45-49$ & 15.935 & 1.129 & 64 & 38 & 56 & 125 & 55 & 791 & 17.064 \\
\hline & Total & 121.472 & 23.018 & 1.167 & 911 & 2.764 & 4.865 & 4.248 & 9.063 & 144.490 \\
\hline
\end{tabular}

Fuente: Elaboración propia a partir de la Encuesta Demográfica de Cataluña, 2007, IDESCAT. Efectivos de mujeres en personas por año.

observación se ha fijado en diez años previos a la migración, de este modo, la variable duración puede adquirir un valor negativo si el nacimiento se produce antes de la migración y un valor positivo si tiene lugar después del momento de migrar hasta pasados veinte años de residencia en España. El valor 0 corresponde al año de llegada a España. Para las mujeres autóctonas, se asigna un valor de la duración superior a los valores de las inmigrantes, y esta duración se convierte en categoría de referencia.

El modelo planteado se ajusta formalmente de la siguiente manera: 


$$
\ln \left(\frac{p_{i}}{1-p_{i}}\right)=\beta_{0}+\sum_{d=-10}^{d=20} \beta_{1, d} d+\sum_{e=15}^{e=49} \beta_{2, e} e
$$

donde $p_{i}$ es la probabilidad de tener un nacimiento vivo, $d$ es la duración de la estancia hasta el momento en que se produce este nacimiento medida como el número de años hasta o desde la migración, y $e$ es la edad de la mujer en el momento del nacimiento. Así, los coeficientes $\beta_{1, d}$ miden los odds ratios o, para simplificar, el riesgo relativo de tener hijos en cada duración de la estancia $d$, en relación con las mujeres autóctonas como categoría de referencia; y los coeficientes $\beta_{2, e}$ son factores de control que permiten eliminar el efecto de la edad en la interpretación de los coeficientes anteriores.

Las curvas de los gráficos representan las odds ratios de la variable «duración», que, como se ha señalado, indica el nacimiento de un hijo en relación con el tiempo transcurrido hasta o desde la migración. Las curvas de fecundidad representadas han sido suavizadas ${ }^{2}$ para interpretar mejor los resultados.

Se han realizado modelos de regresión logística diferenciados para las siguientes tres variables o una combinación de ellas, siempre desde el ejercicio comparativo con la población nacida en España:

Origen. Se ha distinguido entre las tres agrupaciones continentales más representadas, Europa, Africa y América, que constituyen en conjunto un 12,8\% de la muestra, además de las mujeres autóctonas (tabla 2). Se ha excluido del análisis a las mujeres nacidas en países asiáticos, debido al reducido número de casos que representan (un $0,7 \%$ de la muestra general). Entre las mujeres inmigrantes, el 44,6\% son nacidas en países americanos (mayoritariamente latinoamericanos); el 30,8\%, en países europeos, y el 19,7\%, en países africanos (mayoritariamente, en Marruecos).

Edad en el momento de llegar. Como se ha señalado anteriormente, esta variable hace referencia a la llegada a España, a pesar de que el territorio de referencia sea Cataluña. Entre sus categorías, cabe señalar que en aquellas mujeres llegadas a España antes de iniciar su periodo reproductivo (menores de 15 años), no se puede detectar un efecto de la migración propiamente dicho, pero sí observar su comportamiento reproductivo posterior en consideración de su origen migrante. El 38,9\% de las mujeres inmigradas llegaron a España cuando tenían entre 20 y 29 años, mientras que una cuarta parte $(25,1 \%)$ lo hicieron con menos de 20 años (ver tabla 3).

Estado conyugal en el momento de migrar. Mediante la fecha de la migración y las fechas de inicio y fin de cada matrimonio y/o relación estable de cada mujer inmigrante, se ha calculado el hecho de si ésta se encontraba dentro o

2. Las curvas se han suavizado mediante el algoritmo 4253H.Twice de análisis exploratorio de datos (Velleman y Hoaglin, 1981). 
fuera de una unión en el momento de migrar. Aunque el total muestra una distribución equilibrada (un $48 \%$ no estaban unidas frente a un $52 \%$ que sí estaban unidas), existen diferencias destacables por origen - las africanas y las europeas se encuentran predominantemente en pareja al migrar, 57,8\% y $53,4 \%$ respectivamente; mientras que las americanas no lo están en un $51,6 \%$.

Tabla 2. Distribución de la muestra por origen

\begin{tabular}{lrrc}
\hline & $\mathrm{N}$ & $\%$ & $\%$ \\
\hline Nativas & 10.624 & 86,5 & \\
Inmigrantes & 1.657 & 13,5 & 100 \\
Europeas & 511 & 4,2 & 30,8 \\
Africanas & 327 & 2,7 & 19,7 \\
Americanas & 739 & 6,0 & 44,6 \\
Asiáticas & 80 & 0,7 & 4,8 \\
\hline Total & 12.281 & 100 & \\
\hline
\end{tabular}

Fuente: Encuesta Demográfica de Cataluña, 2007, IDESCAT.

Tabla 3. Distribución de la muestra de mujeres inmigradas por origen, edad en el momento de llegar y estado conyugal en el momento de migrar

\begin{tabular}{|c|c|c|c|c|c|}
\hline Europeas & & & & anas & Total \\
\hline $\mathrm{N} \quad \%$ & $\mathrm{~N}$ & $\%$ & $\mathrm{~N}$ & $\%$ & \\
\hline
\end{tabular}

Edad en el momento de llegar

\begin{tabular}{lrrrrrrrr} 
0-9 años & 53 & 10,7 & 31 & 9,6 & 31 & 4,3 & 115 & 7,5 \\
10-19 años & 89 & 17,9 & 79 & 24,5 & 101 & 14,2 & 269 & 17,6 \\
20-29 años & 187 & 37,6 & 125 & 38,8 & 284 & 39,8 & 596 & 38,9 \\
30-39 años & 107 & 21,5 & 66 & 20,5 & 188 & 26,4 & 361 & 23,6 \\
40-49 años & 61 & 12,3 & 21 & 6,5 & 109 & 15,3 & 191 & 12,5 \\
\hline Total & 497 & 100 & 322 & 100 & 713 & 100 & 1.532 & 100 \\
\hline
\end{tabular}

Estado conyugal en el momento de migrar

$\begin{array}{lllllllll}\text { No está en pareja } & 238 & 46,6 & 138 & 42,2 & 381 & 51,6 & 757 & 48,0\end{array}$

\begin{tabular}{lllllllll} 
Sí está en pareja & 273 & 53,4 & 189 & 57,8 & 358 & 48,4 & 820 & 52,0 \\
\hline
\end{tabular}

\begin{tabular}{lllllllll}
\hline Total & 511 & 100 & 327 & 100 & 739 & 100 & 1.577 & 100
\end{tabular}

Fuente: Encuesta Demográfica de Cataluña, 2007, IDESCAT. 


\section{Fecundidad antes y después de la migración: una aproximación descriptiva}

La limitación que supone comparar la fecundidad de mujeres inmigrantes en los países de origen y de destino pasa a menudo por tener que comparar a diferentes mujeres, las que efectúan una migración con las que no lo hacen. Una de las ventajas de poder trabajar con datos longitudinales es la de observar la fecundidad de las mujeres migrantes antes y después de la migración, así como determinar el efecto que el proceso migratorio ha tenido en el comportamiento reproductivo de las mismas.

Es sabido que la fecundidad es una función de la edad y el perfil por edad que proporciona su cálculo aporta una visión de las pautas reproductivas a lo largo del ciclo de vida, sin embargo, la curva obtenida pierde armonía cuando se trata de mujeres inmigrantes, dada la significativa influencia que tiene el momento de la migración en el ciclo vital de dichas mujeres. Tomando como referencia el trabajo de Toulemon (2004) para el caso francés, se han calculado tasas específicas de fecundidad por edad de las mujeres inmigrantes desde el extranjero en Cataluña que tuvieran hijos durante el periodo 1986-2006, diferenciando el grupo de edad a su llegada a España y en comparación con las mujeres no migrantes nacidas en España (gráfico 1).

En una primera comparación de los patrones por edad de autóctonas e inmigrantes, se podrían destacar tres aspectos:

1) A grandes rasgos, tienen una intensidad similar para la edad modal, pero un calendario muy diferente (más joven para las segundas).

2) Las migrantes cuentan con una elevada fecundidad adolescente, diez veces superior a la de las nativas.

3) El número medio de hijos por mujer es de 1,28 para las autóctonas y de 1,80 para las migrantes.

En función de la edad en el momento de llegar, se podrían sintetizar tres pautas diferenciadas correspondientes a tres periodos del ciclo de vida. En primer lugar, quienes llegan de niñas o adolescentes, a quienes no se les puede atribuir un efecto de la migración como tal sobre su reproducción. En segundo lugar, quienes llegaron cuando tenían entre veinte y treinta años, las cuales parecen retrasar el momento de tener hijos a causa de la migración. Y, en tercer lugar, aquellas que llegan a partir de los treinta años, que, si bien han tenido el grueso de su descendencia antes de la migración, parecen mostrar un repunte de la misma como efecto postmigratorio.

Al comparar la fecundidad diferencial en función de la edad en el momento de llegar, observamos que aquellas mujeres que llegaron a España siendo niñas (entre 0 y 12 años) y, por tanto, pasaron parte de su infancia en el país de destino, muestran un calendario tardío, muy similar al de las nativas incluso en la fecundidad adolescente, aunque con una mayor intensidad a todas las edades, con una media de 1,7 nacimientos por mujer. Nótese que, en ellas, la migración en sí misma no ha tenido un efecto como tal, pero su origen inmigrante sí puede ser un factor determinante de su fecundidad. La reproducción 

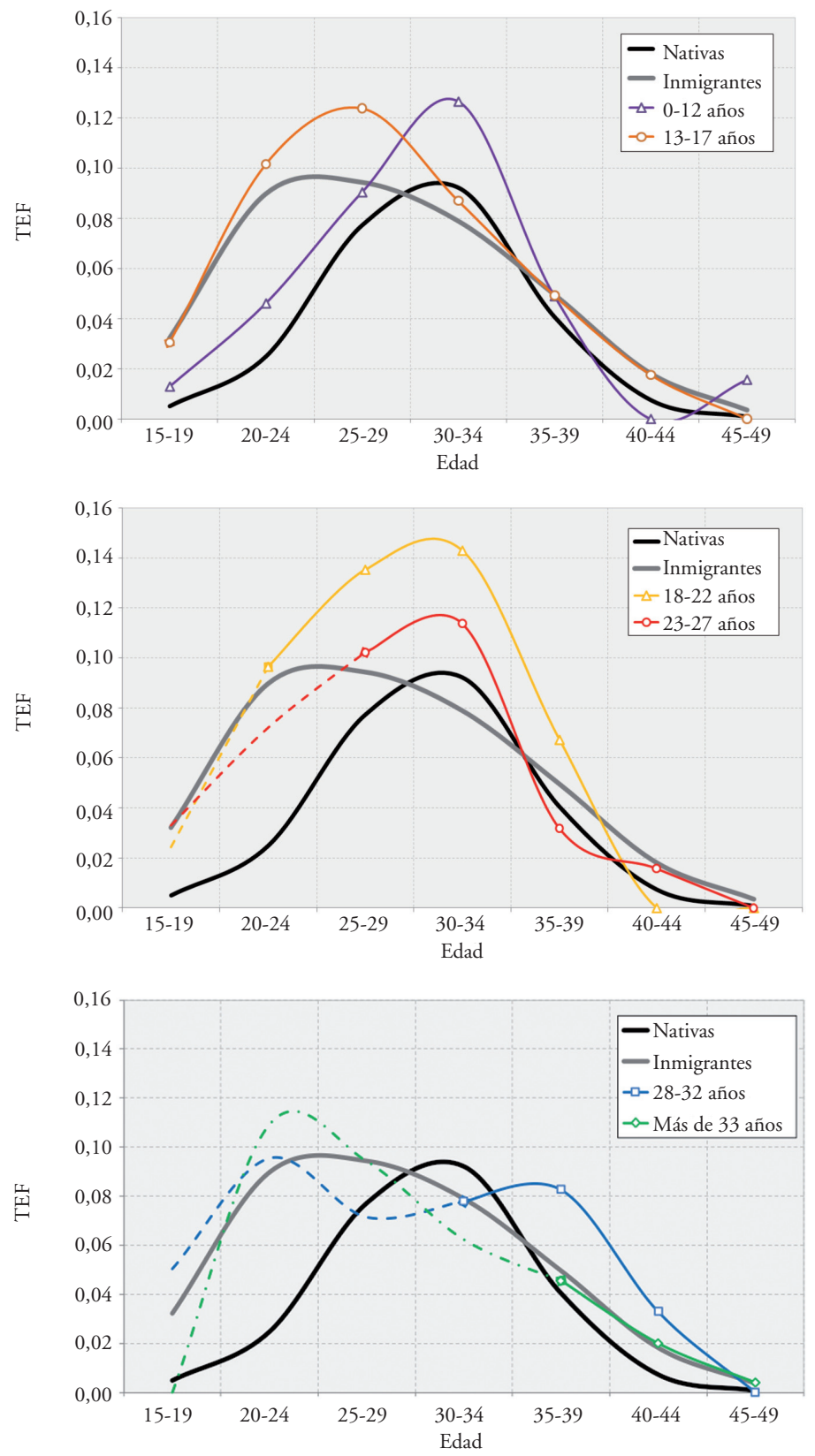

Gráfico 1. Tasas específicas de fecundidad por edad, nativas e inmigrantes según edad en el momento de llegar (Cataluña 1986-2006).

Fuente: Encuesta Demográfica de Cataluña, 2007, IDESCAT.

Nota: La línea punteada indica el periodo previo a la migración, mientras que la línea continua indica el periodo posterior a la migración para cada grupo de edad en el momento de llegar. 
de un calendario tardío, que es un rasgo definitorio de las mujeres nativas, lo podemos interpretar como un signo de adaptación a las pautas de destino. No obstante, también es probable que no estemos ante un cambio de comportamiento como tal, sino que estas mujeres que han crecido en España simplemente se ven, al igual que las españolas, constreñidas a las mismas condiciones materiales y no materiales que explican las pautas de fecundidad de las nativas desde el inicio de su ciclo reproductivo.

Quienes llegaron entre los 13 y los 17 años han vivido su periodo de socialización en el país de origen y migran justo antes de iniciar su ciclo reproductivo. Presentan una curva similar en intensidad al grupo anterior, pero cuentan con un calendario precoz y una todavía elevada fecundidad adolescente propia de las pautas en origen. Su nivel medio total es de 2,05 hijos por mujer. La mayor distancia en el calendario respecto a las nativas podría llevar a considerar un proceso de adaptación incompleto. Otra explicación posible, de nuevo si no se quiere hablar en término de cambio de comportamiento, es que la situación material y no material de estas mujeres es posiblemente distinta de la situación de las mujeres llegadas antes de los 13 años: por ejemplo: su nivel educativo, sus condiciones laborales, el tipo de familia que forman, el porcentaje de uniones mixtas (con otras comunidades) es distinto, por lo cual su pauta de fecundidad difiere de la de las mujeres llegadas más jóvenes.

Entre las mujeres que migraron entre los 18 y los 22 años, o entre los 23 y los 27 años, se aprecia un comportamiento propio que podría denominarse «de contención", puesto que las curvas reproductivas de estas mujeres sugieren un comportamiento en dos fases: en primer lugar, un freno de la fecundidad previa a la migración y, posteriormente, un despunte de la misma inmediatamente después. Las mujeres llegadas en dicho intervalo de edades se han socializado básicamente en el país de origen e incluso han podido formar parejas y tener algún nacimiento previo, pero la migración irrumpe por completo en su ciclo reproductivo, lo cual conlleva un retraso de la maternidad. Ello explica que su edad cúspide para ser madres sea los 31 años (similar a las nativas) y su fecundidad antes de los 25 años sea menor que el grupo anterior. Además, estas mujeres jóvenes constituyen también buena parte de los flujos laborales, por lo que el desarrollo de su actividad puede al mismo tiempo suponer un factor de contención y retraso de la fecundidad. No obstante, una diferencia observada entre quienes llegaron entre los 18 y los 22 años y quienes lo hicieron entre los 23 y los 27 años, es la diferencia en su nivel total de fecundidad, el más elevado de los seis grupos para las primeras, 2,8 hijos por mujer y de 2,35 hijos de media para las segundas.

Una tercera pauta detectada es la de las mujeres que migraron con más de 28 años y en las que se aprecia una división de su reproducción en dos fases. Se trata de mujeres que, en sus países de origen, han desarrollado ya su actividad reproductiva a edades jóvenes (20-24 años) y en las que el proceso migratorio tiene un efecto de reactivación de la fecundidad, especialmente para las que llegaron entre los 28 y los 32 años y mucho menos perceptible para las que migraron con más de 33 . Ese repunte de la fecundidad puede ser 
el efecto de la combinación de diferentes componentes, desde la concepción de la fecundidad en el país de destino como muestra de arraigo, hasta las perturbaciones que la propia migración puede causar en las biografías familiares, como el producto de haber reagrupado al cónyuge, o el de una nueva relación conyugal en España.

Como es sabido, el análisis conjunto de cualquier comportamiento de la población inmigrada esconde importantes diferencias según origen. Por ello, se desglosa a continuación la información anterior para los tres principales grupos continentales -Europa, África y América- y por cada grupo de edad a la llegada. El gráfico 2 da cuenta de la fecundidad diferencial según continente de origen. Las africanas parecen ser las que marcan la tendencia de la curva total de inmigrantes, pues cuentan con los más altos niveles de fecundidad independientemente de la edad de llegada. Es en este colectivo donde el llamado "efecto llegada» se aprecia con mayor ímpetu y de forma más inmediata, incluso en las mujeres llegadas con más de 33 años, donde prácticamente son el único colectivo que experimenta el repunte de la fecundidad tras la migración.

Las europeas, en general, son las que muestran pautas más próximas a las nativas, con un calendario maternal más retrasado. En la observación desagregada, se aprecia, además, cómo las europeas se toman un mayor intervalo de tiempo entre la migración y la descendencia, mientras que en una posición intermedia se encuentran las americanas, con curvas por edad más suavizadas, donde el «efecto llegada» se aprecia de forma más abrupta entre quienes llegaron entre los 23 y los 27 años.

Por otra parte, las mujeres que llegaron con más de 28 años comparten una misma pauta a edades tempranas en los países de origen, tanto en intensidad como en calendario, pero, a partir de los 25 , sus comportamientos divergen de forma que las africanas se caracterizan por una alta intensidad en relación con el total del grupo, mientras que las europeas presentan la pauta contraria, de baja intensidad, incluso por debajo de las nativas.

\section{Nacimientos hasta y desde la migración: modelización}

La hipótesis principal de la que parte este trabajo es que las diferencias en el comportamiento reproductivo entre las mujeres nacidas en el extranjero y las nacidas en España se explican de forma complementaria desde la edad de la migración y desde el país de origen. Para una mejor comparación de la fecundidad de ambas, se recurre a continuación a un procedimiento de análisis multivariable.

Dicho análisis mide el riesgo relativo de tener un hijo para las mujeres inmigrantes, en relación con el riesgo de las mujeres autóctonas, en función del tiempo transcurrido hasta y desde la migración para las primeras y controlando el efecto de la edad para ambas. Para duraciones negativas, los valores de este riesgo indican el nivel relativo de la fecundidad de las inmigrantes en sus países de origen. El valor en la duración 0 mide esta fecundidad relativa 
en el año en que efectúan la migración, mientras que en duraciones positivas se trata de medir el riesgo una vez han llegado a España. Si los valores obtenidos son superiores a 1, significa una fecundidad más alta para las inmigrantes que para las autóctonas a igual edad, siendo ésta más baja para los valores inferiores a 1 .
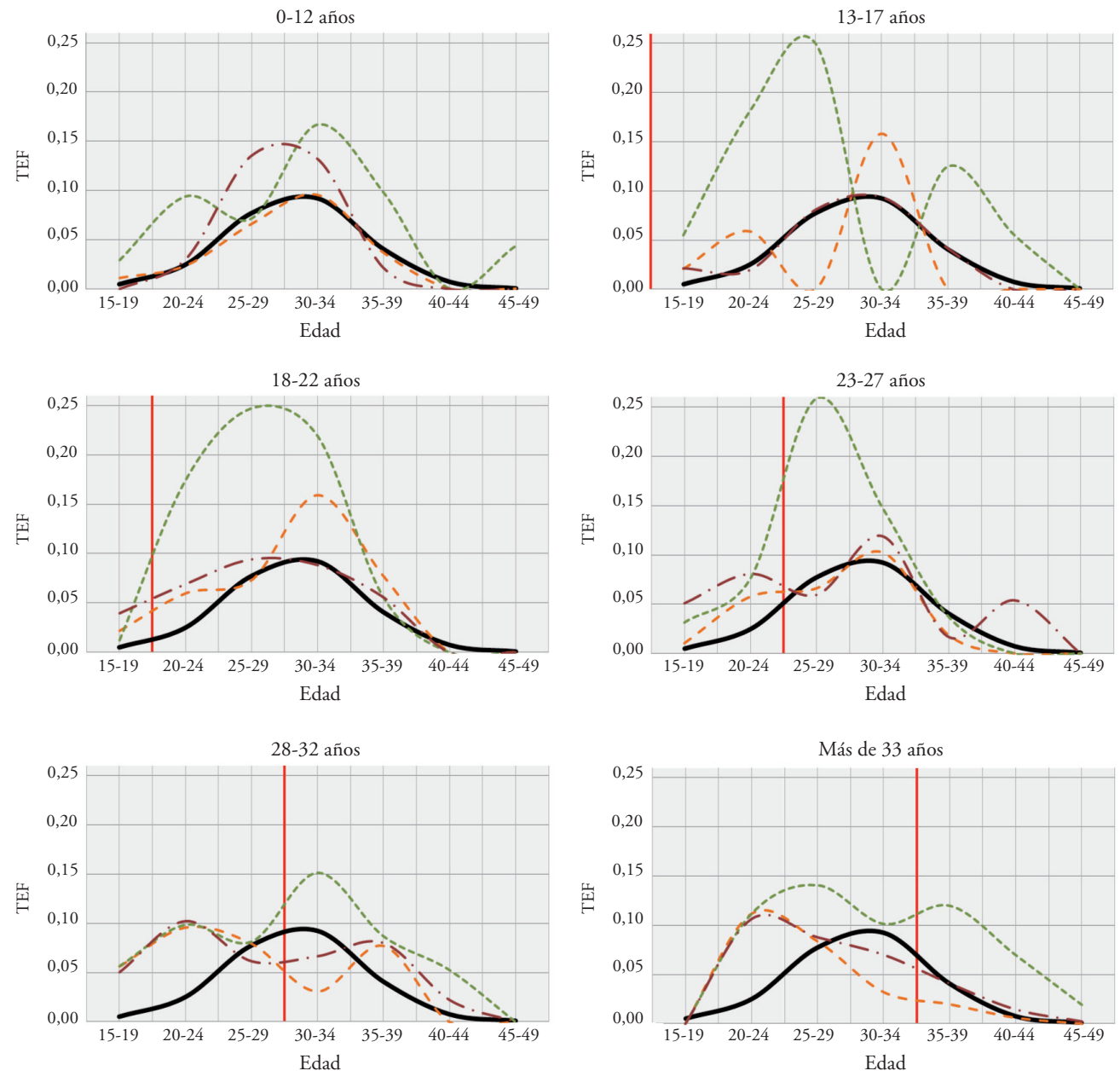

Nativas $\quad--$ Europeas

----Africanas $\quad-\cdot$ Americanas

Gráfico 2. Tasas específicas de fecundidad por edad, nativas y grupos continentales por cada grupo de edad en el momento de llegar (Cataluña 1986-2006).

Fuente: Encuesta Demográfica de Cataluña, 2007, IDESCAT. 
A través de los resultados mostrados en el gráfico 3 por los modelos de regresión logística en tiempo discreto, podemos establecer, para el total de mujeres inmigradas, tres efectos tipo que se corresponden con las principales hipótesis teóricas sobre migración y fecundidad:

Efecto anticipación o interrupción (hipótesis de interrupción). Este efecto consiste en una reducción de la fecundidad durante los años previos a la migración que conlleva un retraso de los nacimientos en el ciclo de vida de las mujeres migrantes. Se presupone, por tanto, un control efectivo de la fecundidad en previsión del proceso migratorio. De este modo, hasta los 5 años previos a la migración, los niveles de fecundidad de las mujeres en el país de origen eran superiores a los de las autóctonas en Cataluña, mientras que, en los 5 años previos, este nivel cae por debajo de la fecundidad de las autóctonas. Este descenso de la fecundidad previo a la emigración se puede explicar de al menos dos maneras distintas y opuestas: las mujeres anticipan su migración y esperan hasta después de su llegada para tener los hijos que hubieran tenido igualmente en su país de origen de no haber emigrado. Mientras que otra explicación plausible podría ser un empeoramiento de las condiciones materiales y familiares de estas mujeres, que podría ser la razón que desencadena la migración.

Efecto llegada (hipótesis de interrelación de eventos). Este efecto supone un incremento prematuro del riesgo relativo de tener un hijo al llegar a España en los años que siguen a la migración. Su interpretación se asocia con la recuperación

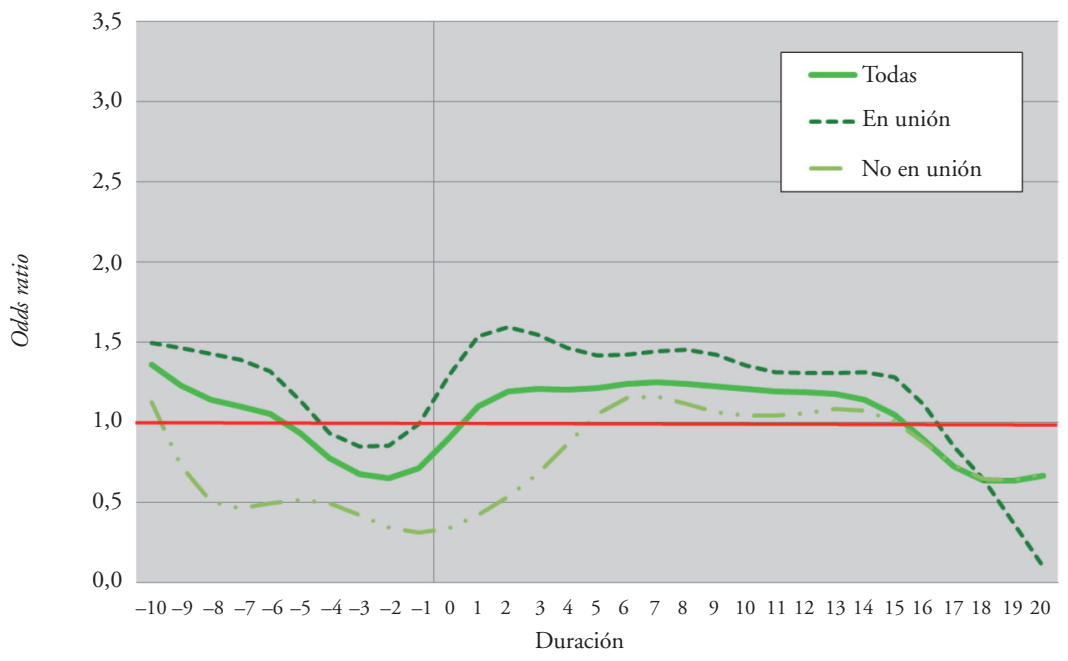

Gráfico 3. Odds ratio de fecundidad de las inmigrantes en Cataluña en relación con las mujeres autóctonas, según la duración desde o hasta el año en que se produce la migración y el estado conyugal en el momento de migrar.

Fuente: Encuesta Demográfica de Cataluña, 2007, IDESCAT. 
de la fecundidad retrasada o interrumpida en los años previos a la migración y se vincula a procesos de formación familiar, ya sea por reagrupación del cónyuge en el caso de hombres que habitualmente migran antes que sus esposas, ya sea por formación de nuevas parejas en el país de destino en el caso de mujeres que migran solas.

Efecto adaptación (hipótesis de adaptación). En este caso se observa la aproximación progresiva de la fecundidad de las migrantes hacia la de las mujeres autóctonas a medida que aumenta el número de años de residencia en el país de destino. Superado el efecto llegada, el riesgo relativo de la fecundidad se mantiene un $20 \%$ por encima del nivel de las autóctonas hasta pasados quince años tras la migración, después de los cuales el riesgo disminuye por debajo de 1, es decir, es inferior al nivel de las autóctonas, evolución que se interpreta como un efecto de adaptación o convergencia del comportamiento reproductivo.

En torno a la modelización de estos tres efectos principales giran los resultados de este trabajo. A continuación, se observa cómo el estado conyugal puede cambiar la interpretación de los diferentes efectos detectados. En el gráfico 3 se muestra la corrección de la pauta de fecundidad del total de inmigrantes una vez se tiene en cuenta el hecho de encontrarse dentro o fuera de una unión conyugal (matrimonial o consensual) en el momento de migrar, siempre controlando o anulando el efecto de la edad en la comparación con las autóctonas. Así, los resultados sugieren que las mujeres que vivían en pareja tuvieron un efecto anticipación de menor intensidad y duración que las no unidas, así como un rápido efecto recuperación y un progresivo efecto adaptación observable a partir del tercer año de residencia, aunque, a igual edad, el nivel de su fecundidad es considerablemente superior a las autóctonas durante los primeros dieciséis años de residencia. En segundo lugar, en aquellas mujeres que no vivían en pareja cuando migraron, no se observa apenas el efecto anticipación, mientras que el efecto llegada se suaviza y se retrasa durante los primeros años de residencia, contando con una intensidad superior a la de las nativas sólo a partir de los primeros cinco años de residencia, tiempo en que establecen nuevas uniones y tienen, en la mayoría de los casos, sus primeros hijos.

Cabe señalar que la diferencia observada entre ambos grupos de mujeres, en cuanto al efecto llegada o recuperación, es la que explica por qué motivo no se observa un efecto adaptación en la curva del total de inmigrantes a causa de la compensación que ejercen unas y otras sobre el total.

En este mismo sentido, la observación de mujeres inmigrantes en su conjunto aporta una pauta general del comportamiento reproductivo, pero oculta una gran heterogeneidad en función no sólo de los diferentes orígenes, sino también de la edad de esas mujeres cuando migraron. Es esencial abordar ambos aspectos para disponer de una visión más precisa de la complejidad del fenómeno.

El gráfico 4 representa los riesgos relativos de las diferentes curvas de fecundidad de las inmigrantes en Cataluña según su edad a la llegada a España 
en relación con las mujeres autóctonas e incluye también el conjunto de las mujeres inmigradas. Asimismo, los modelos representados controlan por la edad al tener el hijo.

De este modo:

- Las mujeres que llegan con 0-9 años, como es obvio, no pueden mostrar un efecto de la migración sobre su fecundidad como tal, pero sí el posible efecto de su origen inmigrante, aunque se hayan socializado en el país de destino. En este sentido, se esperaría una proximidad al comportamiento de las nativas y, sin embargo, se observa una probabilidad de tener hijos mayor que el colectivo de referencia debido a un calendario anticipado, pues comienzan a tenerlos a partir de los diez y más años de residencia, es decir, cuando alcanzan una edad en torno a los 20 años.

- Las mujeres llegadas con 10-19 años parecen tener sus hijos justo en torno al momento de la migración. Esta pauta podría interpretarse como un efecto causal según el cual, para ellas, es precisamente la maternidad adolescente la que actúa como detonante de la migración, es decir, han migrado al tener un hijo o al saber que iban a tenerlo. Este ejemplo representaría la otra cara de la interacción entre fecundidad y migración, de modo que la segunda es un efecto de la primera, y no al contrario. En ellas no existe efecto anticipación, pues se encuentran apenas en el inicio del periodo reproductivo y, en todo caso, el efecto llegada se anticipa a la propia llegada. Progresivamente sí se alcanza un efecto convergencia a medida que aumenta

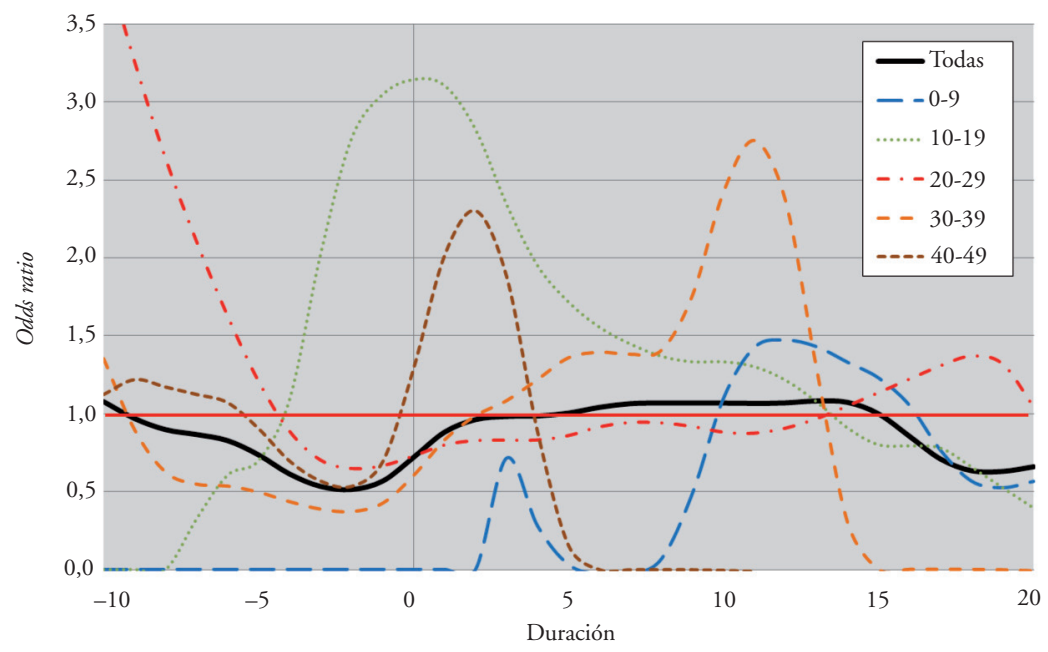

Gráfico 4. Odds ratio de fecundidad de las inmigrantes en Cataluña en relación con las mujeres autóctonas, según la duración desde o hasta el año en que se produce la migración y por edad a la llegada a España.

Fuente: Encuesta Demográfica de Cataluña, 2007, IDESCAT. 
la duración. Una posible hipótesis podría ser la de aquellas mujeres en cuyo proyecto migratorio está el tener un hijo en el país de destino por el valor añadido que supone en términos de residencia legal, aunque en la práctica su incidencia es muy limitada y relegada a un número mínimo de mujeres en situación irregular.

- Entre las que llegan con 20-29 años, el gráfico indica que han tenido a sus hijos con un calendario muy temprano, en torno a cinco a diez años antes de migrar, y desde los cinco años previos comienza el efecto anticipación. Sin embargo, una vez migran, el efecto llegada es muy leve y la intensidad de su fecundidad es muy próxima a la de las nativas. Estas mujeres en pleno periodo de actividad y probablemente con descendencia en el país de origen es posible que controlen su reproducción durante el primer periodo de residencia hasta establecerse económicamente, de forma que el efecto convergencia se anticipa. Ello explicaría que, a partir de los diez años de residencia, se observe un repunte de la curva de fecundidad que podría deberse tanto a nuevas uniones y segundas nupcias, como a la reagrupación del cónyuge.

- Por su parte, quienes llegaron con 30-39 años parecen ser las que tienen un efecto anticipación más intenso y de mayor duración prácticamente desde los ocho años previos a la migración (mientras que en los otros grupos suele comenzar en cuatro o cinco años previos). No obstante, cabe considerar que no sea un efecto de la previsión de migrar, sino la consecuencia de haber tenido ya a sus hijos durante la veintena. Una vez migran, muestran un marcado, pero no inmediato, efecto llegada que se incrementa hasta los diez años de residencia (40-49 años de edad en las mujeres). La reagrupación familiar y el establecimiento de nuevas uniones son probablemente los factores que explican la fecundidad postmigratoria de estas mujeres.

- Finalmente, aquellas mujeres que llegaron con 40-49 años muestran de igual modo la anticipación, aunque la intensidad de su fecundidad a edades jóvenes sale del campo de observación (antes de -10 años). Se observa un efecto llegada inmediato, asociado al hecho de que migran justo en los años finales de su periodo de edad fértil.

También los comportamientos son dispares si se observan desde la perspectiva del continente de origen. El gráfico 5 representa esas diferencias para los tres orígenes continentales con mayor representación -Europa, África y América- comparado con el conjunto de mujeres inmigradas y de nuevo en relación con las nativas como categoría de referencia. Los aspectos más relevantes del análisis por origen son:

- Las africanas muestran el comportamiento más diferencial respecto al resto de grupos con una intensidad de la fecundidad sobresaliente antes y después de la migración. Aun contando con un efecto anticipación, éste es el menos incisivo de los tres, pues el descenso partía de cotas de fecundidad más elevadas, mientras que su efecto llegada es el más acentuado e inme- 
diato. Asimismo, se observa, a partir del tercer año de residencia, un leve pero continuo efecto convergencia. La alta fecundidad nada más llegar a España de estas mujeres se podría explicar por varias razones. Por una parte, son orígenes caracterizados por una migración pionera masculina que posteriormente reagrupa a sus esposas, por lo que la llegada de mujeres africanas responde más a los flujos de reagrupación que a los laborales. Por otra parte, se debe recordar, además, que el colectivo africano cuenta con una fecundidad más elevada en origen de forma general, y tener hijos en España, a pesar de los costos que supone la migración, implica una serie de garantías sociales, educativas y sanitarias con las que no siempre cuentan en los países de origen.

- Las europeas son el único colectivo que, prácticamente a lo largo de todo el periodo, muestra una intensidad de la fecundidad inferior a las nativas. A diferencia de americanas y de las africanas, su efecto anticipación no es demasiado pronunciado. El efecto llegada se intensifica en los dos primeros años de residencia y se mantiene hasta los siete años. Después de los 14 a los 16 años de residencia, se aprecia un repunte de la fecundidad probablemente producto de nuevas y segundas uniones. En este caso, se debe advertir que buena parte de los países europeos tienen en común, junto a España, el hecho de ser contextos de baja o muy baja fecundidad si se compara con el resto de orígenes.

- Para las americanas, la principal distinción es que el efecto llegada es posterior, pues se observa a partir de los cuatro años de duración. Dicho efecto

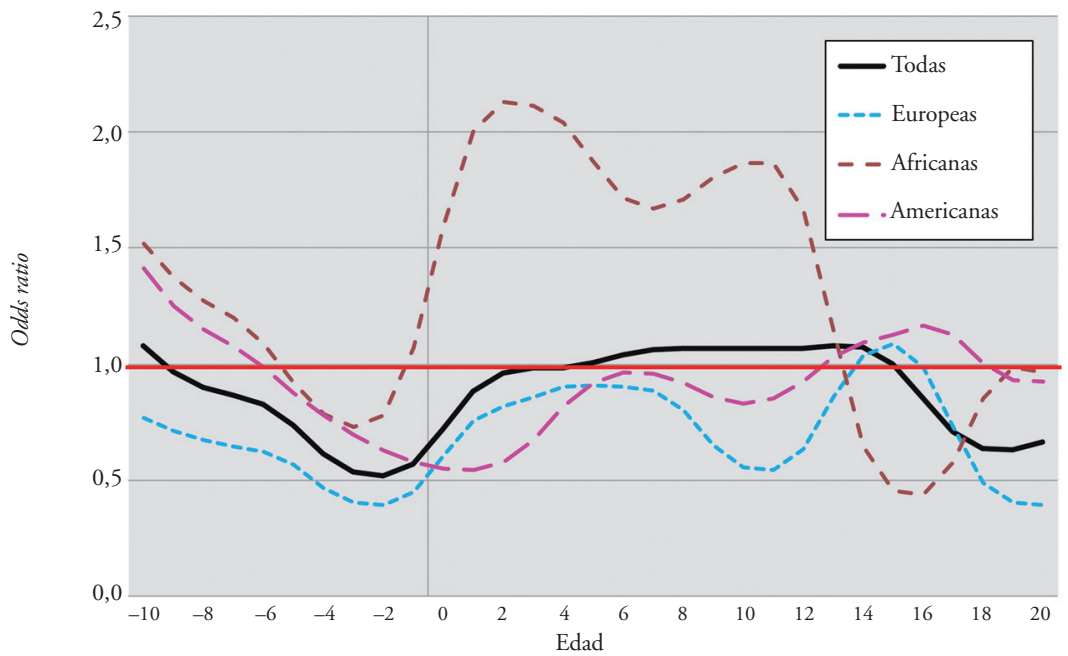

Gráfico 5. Odds ratio de fecundidad de las inmigrantes en Cataluña en relación con las mujeres autóctonas, según la duración desde o hasta el año en que se produce la migración y por continente de nacimiento.

Fuente: Encuesta Demográfica de Cataluña, 2007, IDESCAT. 

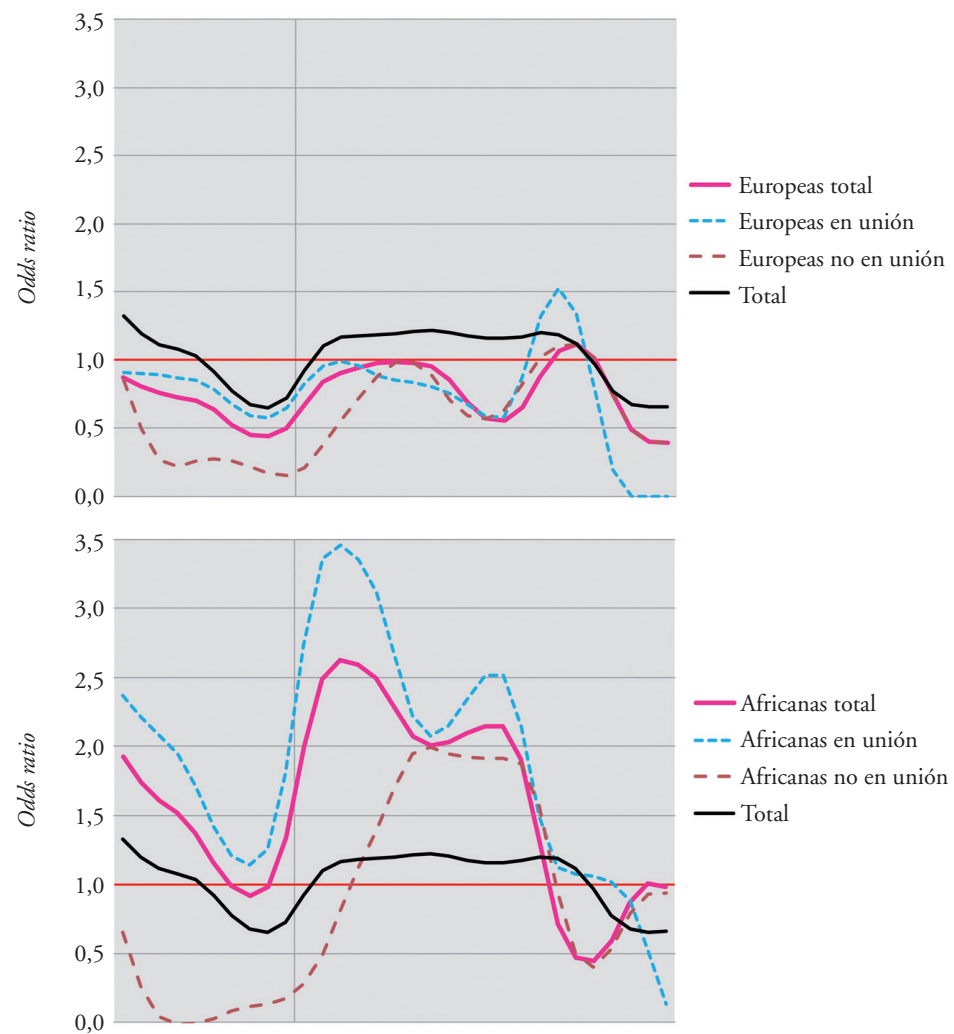

- Africanas total

--- Africanas en unión

- - Africanas no en unión

- Total

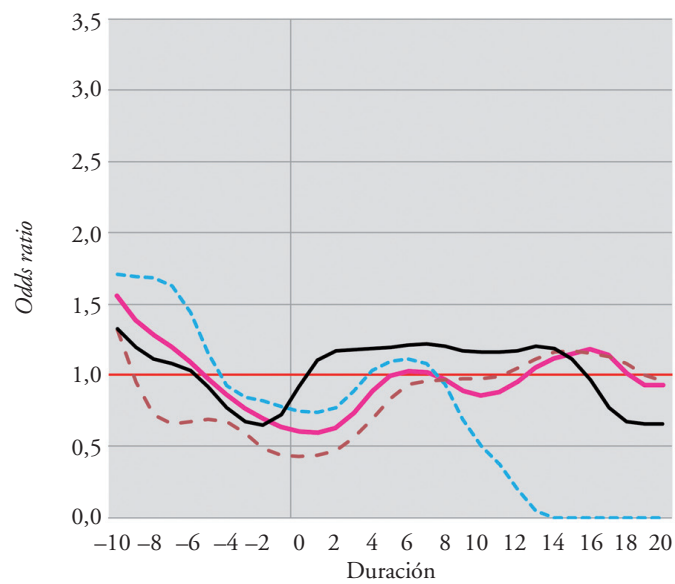

- Americanas total

--- Americanas en unión

- - Americanas no en unión

- Total

Gráfico 6. Odds ratio de fecundidad de las inmigrantes en Cataluña en relación con las mujeres autóctonas, según la duración desde o hasta el año en que se produce la migración y por continente de nacimiento y estado conyugal en el momento de migrar.

Fuente: Encuesta Demográfica de Cataluña, 2007, IDESCAT. 
parece ser más inmediato en africanas y europeas que en americanas, es decir, estas últimas alargan más la interrupción de la fecundidad, posiblemente porque vienen solas (migración feminizada), puesto que dejan a sus cónyuges en origen, $\mathrm{o}$, en el caso de que lleguen solteras, porque tardan un tiempo en formar pareja en España. Un hecho característico en estas mujeres es que su fecundidad parece aumentar paulatinamente a medida que pasan los años de residencia, pero a niveles muy próximos a la población autóctona.

En un análisis más específico, se observan, en el gráfico 6, los patrones de fecundidad por edad según el estado conyugal de la mujer en el momento de migrar y para cada uno de los tres orígenes. Los tres efectos observados - anticipación, recuperación y convergencia- se pueden apreciar en el caso de las mujeres nacidas en países europeos. Entre las europeas que no se encontraban en unión en el momento de migrar, a diferencia de aquellas que migraron estando unidas, el efecto anticipación apenas existe y la recuperación de la fecundidad tiene lugar a partir de los cinco años de residencia.

Las diferencias entre unidas y no unidas al migrar son especialmente destacables en el caso de las mujeres nacidas en países africanos. Las mujeres africanas que migraron sin estar en unión contaban con una muy baja fecundidad en el periodo premigratorio y no experimentarán un incremento de la misma hasta los seis años de residencia en España. En cambio, las africanas que sí se encontraban en unión conyugal al migrar, experimentan un efecto llegada inminente, que incluso se anticipa al momento de la migración. Por otra parte, en estas mujeres es posible apreciar con claridad un proceso de convergencia o adaptación, dado el paulatino descenso de su fecundidad a medida que aumentan los años de residencia en España. Esto sugeriría que el comportamiento de las africanas está fuertemente marcado por el estado conyugal en el que migran, pues, en su mayoría, migran unidas.

Por último, la peculiaridad del caso americano radica en su caracterización como migración feminizada. Ello repercute en el hecho de que las mujeres que migraron unidas cuenten con un efecto recuperación algo más tardío en comparación con europeas o africanas, lo cual se interpretaría desde el tiempo transcurrido hasta que reagrupan a sus cónyuges desde el país de origen. En este colectivo, la fecundidad entre los dos grupos es cercana entre sí, incluso antes de la migración, y muy próxima al nivel de las nativas, por lo que se convierten en el grupo en el que menor incidencia tiene la discontinuidad provocada por la migración. En este caso, no se observa una compensación de la fecundidad postmigratoria que cubra el hueco marcado por el efecto anticipación, como sí ocurre en europeas y africanas.

La relativa alta fecundidad que, independientemente del origen, tienen las mujeres que no estaban unidas al migrar a partir de duraciones mayores de doce años, es el producto de la entrada en las edades más fecundas de aquellas migrantes que llegaron a España a edades jóvenes o durante su infancia y, por definición, se engloban en la categoría de no unidas. 


\section{Conclusiones}

En este trabajo, se ha analizado si existe un efecto del proceso migratorio y del tiempo de residencia en España sobre el comportamiento reproductivo de las mujeres inmigradas a través de la forma que adoptan sus curvas de fecundidad por edad.

Sin duda, la respuesta a la pregunta planteada es afirmativa y se han constatado diversas consecuencias de la interacción entre migración y fecundidad para el caso español que se manifiestan de forma heterogénea en función del origen y la edad a la llegada de las mujeres. En primer lugar, se puede hablar de un estadio intermedio de inmersión en el contexto económico y cultural de la sociedad de destino entre aquellas mujeres que llegaron de niñas y crecieron en España (generación 1.5). Su calendario cercano al de las nativas junto a una intensidad ligeramente superior puede ser la respuesta a un proceso de socialización desarrollado aún entre dos contextos: el de origen transmitido a través de la familia y el de destino. Diferente es el caso de las mujeres llegadas en su adolescencia que han concentrado su maternidad en torno al momento de la migración. La estrecha vinculación entre fecundidad y migración a esta edad podría dar lugar a una doble interpretación en torno a la relación causaefecto: 1) que la migración sea un efecto de la maternidad, es decir, que un nacimiento o un embarazo funcionen como detonante de la decisión de migrar, o bien 2) que la maternidad sea un efecto de la migración, lo cual se sustenta en diversas posibles explicaciones, como la reunificación familiar, el matrimonio o una nueva relación de pareja, o incluso la creencia de que tener un hijo en el país de destino comporta beneficios de carácter legal (aunque esta última hipótesis afectaría a un mínimo de mujeres y, en mayor medida, a aquellas que se encuentren en situación irregular).

En segundo lugar, se observa cómo las mujeres llegadas durante su veintena dividen su reproducción entre origen y destino. Si bien ya han tenido hijos a edades tempranas, han extendido en unos casos y han reactivado en otros su reproducción una vez se han instalado en España. El flujo de mujeres inmigrantes en plena edad de actividad laboral podría explicar, como muestran los modelos de duración, que estas mujeres, aún con un margen temporal para la reproducción, necesiten un periodo previo de instalación y adaptación, por lo que el mayor repunte de su fecundidad se aprecia tras los diez años de residencia en España.

La tercera pauta observada es la de aquellas mujeres que llegaron a España a partir de los 30 años. Se trata de mujeres que ya han tenido el grueso de su descendencia a edades tempranas en sus países de origen, pero, como producto de la migración — ya sea por reagrupación familiar o por nuevas uniones-, han experimentado un repunte de su fecundidad en un momento tardío de su etapa reproductiva.

En definitiva, se observa como, dependiendo del momento en el ciclo de vida en que la mujer migra, el efecto es uno u otro. Y, en términos generales, se pueden identificar en las curvas de fecundidad diferentes efectos comunes a todas ellas, en mayor o menor grado. El efecto anticipación es generalizado y 
consiste en un control y en un retraso de la fecundidad en los cuatro o cinco años previos a la migración. Las mujeres que migraron en su niñez y en su adolescencia escapan a este efecto por razones obvias y, en el caso de las adolescentes, muestran lo que se podría denominar un «efecto causal», que vincula estrechamente migración y fecundidad de manera casi simultánea. Aquellas mujeres que contuvieron su maternidad en los años previos a la migración experimentan tras ella un efecto llegada que supone una alta intensidad del fenómeno en los primeros años de residencia, probablemente muy vinculada a la reagrupación familiar. Sin embargo, entre aquellas que migraron en su veintena y en su treintena, el efecto llegada existe, pero no es tan intenso inicialmente, sino que se dilata en el tiempo y, tras un periodo superior a los ocho años de residencia, se intensifica si contemplamos que pueda tratarse de mujeres que llegaron en pleno periodo de actividad laboral y han necesitado un tiempo de incorporación social al nuevo contexto que conllevara incluso nuevas relaciones conyugales. Finalmente, se puede concluir que, tras una alta fecundidad postmigratoria, se aprecia un efecto convergencia o adaptación observable entre las mujeres que llegaron jóvenes. Se debe remarcar que, habitualmente, se sobrestima el nivel de fecundidad de las migrantes dada su alta fecundidad en los primeros años tras la migración (efecto llegada), que es en realidad el resultado de la interrupción previa y el consiguiente retraso de la maternidad. Del mismo modo, la caída de la fecundidad tras los primeros años de residencia se puede estar malinterpretando como un proceso de convergencia o adaptación, cuando no es más que la consecuencia natural de una rápida recuperación del tiempo perdido.

Las conclusiones hasta aquí presentadas responden a un perfil general de la mujer migrante, sin embargo, como se ha observado en el texto, existen algunas diferencias por origen que es necesario tener presentes. Las mujeres africanas presentan el comportamiento más diferencial en comparación a las nativas y al resto de inmigrantes. Su fecundidad es la más intensa, por lo que experimentan el menor efecto anticipación y el más agudo efecto llegada. La migración africana femenina se caracteriza por tratarse de mujeres que llegan en gran medida como reagrupadas o para contraer matrimonio, y su inserción laboral es menor que la de otros colectivos. Si a ello le añadimos el hecho de que su fecundidad en origen es también elevada y que tener hijos en España cuenta con el valor añadido de una serie de garantías sociales, sanitarias y educativas, no es sorprendente que, tras la migración, contribuyan de forma importante a la natalidad española. Mientras la africana es una migración masculinizada que posteriormente reagrupa a sus mujeres, la americana (latinoamericana) se caracteriza por el caso contrario. Los flujos llegados desde América han sido tradicionalmente feminizados, lo cual explica que, en las mujeres migrantes, la transición a la maternidad postmigratoria requiera de un periodo previo de residencia en España, hasta que reagrupen a sus cónyuges, si migraron unidas, o hasta que conformen nuevas relaciones conyugales, si migraron solteras. Las europeas son las que muestran el perfil reproductivo más próximo a la población nativa, si bien es cierto que buena parte de los países europeos se 
caracterizan por una baja fecundidad en relación con otros orígenes. Por otra parte, la ausencia de impedimentos legales y libre circulación por el territorio europeo podría explicar que la fecundidad de las europeas no sea tan sensible a los efectos asociados a la migración.

Los resultados aquí presentados constituyen una exploración preliminar de los datos a partir de la cual se nos plantean ciertos interrogantes sobre los que profundizar en el futuro. El principal problema a resolver es el que hace referencia a la significación estadística de los coeficientes que miden los diferentes efectos en relación con la duración (hasta o desde la migración) sobre la fecundidad, cuando éstos son significativamente diferentes de 1 (cuando el nivel de fecundidad de las migrantes es diferente al de las mujeres autóctonas). Dado que los coeficientes edad a edad son demasiado numerosos, sería necesario ajustar un modelo paramétrico que, mediante una función matemática, ajustara las curvas de duración a sólo tres o más parámetros, comprobando la significación estadística de cada uno de ellos. Asimismo, sería de gran interés explorar las diferencias según nivel educativo, actividad o número total de hijos vivos.

\section{Referencias bibliográficas}

Alders, M. (2000). "Cohort fertility of migrant women in the Netherlands». BSPSNVD-URU Conference, 31 de agosto y 1 de septiembre de 2000. Utrecht: Statistics Netherlands.

Andersson, G. (2001). "Childbearing patterns of foreign-born women in Sweden». MPIDR Working Paper 2001-011. Rostock: Max Planck Institute for Demographic Research.

Bledsoe, C. (2004). «Reproduction at the Margins: Migration and Legitimacy in the New Europe». Demographic Research, vol. Special Collection 3.

Bledsoe, C. et al. (2007). "High fertility Gambians in low fertility Spain: The dynamics of child accumulation across transnational space». Demographic Research, $16,375-412$.

Carter, M. (2000). «Fertility of Mexican immigrant women in the U.S.: A closer look». Social Science Quarterly, 81 (4), 1073-1086.

Castro-Martín, T. y Rosero-Bixby, L. (en prensa). "Maternidades y fronteras: la fecundidad de las mujeres inmigrantes en España». Revista Internacional de Sociología (RIS).

Devolder, D. y Galizia, F. (2010). «Interrelaciones entre migración internas y fecundidad en España durante el siglo xx». IX Congreso de la ADEH, Sao Miguel (Azores).

Frank, R. y Heuveline, P. (2005). "A crossover in Mexican and Mexican-American fertility rates: Evidence and explanations for an emerging paradox». Demographic Research, 12 (4), 77-104.

Gordon, M. (1964). Assimilation in American life: The role of race, religion, and national origin. Nueva York: Oxford University Press.

KaHn, J. R. (1994). "Immigrant and Native Fertility during the 1980s: Adaptation and Expectations for the Future». International Migration Review, 28 (3), 501-519. 
Kulu, H. (2003). «Migration and Fertility: Competing Hypotheses Re-examined». Demographic Research, 35, 40. Rostock: Max Planck Institute for Demographic Research.

Lindstrom, D.P. y Giorguli, S. (2007). "The interrelationship between fertility, family maintenance, and Mexico-U.S. migration». Demographic Research, 17 (28), 821-858.

Milewski, N. (2007). «First child of immigrant workers and their descendants in West Germany: Interrelation of events, disruption, or adaptation?». Demographic Research, 17 (29), 859-896.

Parrado, E. A. y Morgan, S. P. (2008). «Intergenerational Fertility among Hispanic Women: New Evidence of Immigrant Assimilation». Demography, 45 (3), 651-671.

Roig, M. y Castro, T. (2007). "Childbearing Patterns of Foreign Women in a New Immigration Country: The Case of Spain». Population-E, 62 (3), 351-380.

Toulemon, L. (2004). "Fertility among immigrant women: new data, a new approach». Population and Sociétés, 400, 4.

Toulemon, L. y Mazuy, M. (2006). "Comment prendre en compte l'âge à l'arrivée et la durée de séjour en France dans la mesure de la fécondité des immigrants?». Documents de Traval-INED, 120.

Velleman, P. F. y Hoaglin, D. C. (1981). Applications, Basics, and Computing of Exploratory Data Analysis. Boston, MA: Duxbury Press. 